\title{
Trajectories of objectively measured sedentary time among secondary students in Manitoba, Canada in the context of a province-wide physical education policy: A longitudinal analysis
}

\author{
Fei Zuo, MPH, ${ }^{1}$ Melisa Comte, MSc, ${ }^{2}$ Jannice So, $\mathrm{MPH},{ }^{3}$ Laura Rosella, $\mathrm{PhD},{ }^{3}$ Jonathan McGavock, $\mathrm{PhD},{ }^{2}$ \\ Erin Hobin, $\mathrm{PhD}^{1,3,4}$
}

\begin{abstract}
OBJECTIVES: Canadian adolescents' sedentary behaviour (SB) is poorly understood and greatly understudied compared to physical activity (PA). Accumulating evidence suggests that SB poses long-term health risks regardless of PA levels. To design effective interventions that target SB, it is critical to first understand adolescents' sedentary time (ST) trajectories in a Canadian context. Therefore, we examined longitudinal trajectories of Manitoba students' ST from 2008 to 2011 and identified associated factors in the context of a province-wide physical education (PE) policy.
\end{abstract}

METHODS: Secondary schools offering grades 9 through 12 were randomly selected in blocks to represent the urban and rural geography of Manitoba. In each selected school $(n=31)$, a convenience sample of grade 9 or 10 PE classes was recruited, leading to a final sample of 447 students. To assess ST, participants wore accelerometers on 7 consecutive days at baseline (2008) and during at least one follow-up period (2009, 2010 and 2011).

RESULTS: At baseline, students accumulated an average of 540 minutes/day of ST. Over the course of secondary school, students' ST trajectories remained stable. Females compared to males had a slightly higher rate of decline in ST $(p=0.035)$, adjusting for socio-demographic variables. ST trajectories were not associated with baseline PA, body mass index and school neighbourhood socio-economic status.

CONCLUSION: Adolescent ST remained high throughout secondary school. SB may be well established by early adolescence and track through late adolescence. Our findings suggest the potential need for additional interventions to reduce SB before and over the course of secondary school.

KEY WORDS: Sedentary time; linear growth model; longitudinal analysis

La traduction du résumé se trouve à la fin de l'article.

Can J Public Health 2016;107(1):e23-e29 doi: $10.17269 / \mathrm{CJPH} .107 .5238$

$\mathrm{P}$ articipation in physical activity (PA) has long been recognized as a key component to healthy living across the life span. ${ }^{1}$ Despite this knowledge, PA levels of Canadians continue to remain low and the prevalence of overweight and obesity has risen over the past several decades, particularly among adolescents. $^{2}$ In Canada, less than $7 \%$ of adolescents accumulate the recommended minimum of 60 minutes of moderate-tovigorous-intensity physical activity (MVPA) per day, ${ }^{3}$ and most accumulate more than 9 hours of total sedentary time (ST) daily. ${ }^{4}$ The phenomenon of low PA coupled with high amounts of ST among young Canadians is raising alarm among local scientific communities and public health experts due to potential association with chronic disease risk factors. ${ }^{1}$

A growing body of evidence now links sedentary behaviour (SB), characterized by minimal energy expenditure (i.e., $\leq 1.5$ metabolic equivalents) during waking hours, to adverse health outcomes, including weight gain, ${ }^{5,6}$ increased metabolic risks, ${ }^{6-9}$ and early mortality, ${ }_{10}^{10}$ regardless of PA levels. ${ }^{711,12}$ Moreover, individuals can meet the minimum MVPA recommendations per day but exceed SB recommendations by staying in a prolonged sitting or reclining posture throughout the remainder of the day. ${ }^{13}$ In light of the growing concern of low PA and high sedentariness among young Canadians as well as their independent health risks, public health efforts make recommendations for increasing PA as well as limiting ST. ${ }^{1,3}$ Although both PA and ST are issues, ST has been less often the subject of investigations to improve health of adolescents. ${ }^{14}$ While available evidence suggests that interventions with a focus on PA may result in a modest reduction in ST among adults, ${ }^{14}$ no existing research in Canada has evaluated the potential of population-based policies promoting PA on adolescents' ST trajectories.

Adolescence may be an important developmental period during which SB is established. ${ }^{15,16}$ According to the National Health and Nutrition Examination Survey (NHANES 2003-2004) US adolescents (aged 16 to 19) spent 2 hours more per day being sedentary as compared to US children (aged 6 to 11 ). ${ }^{15}$ Similarly, ST increased by 1.5 hours per day from age 12 to 16 among participants of the Avon Longitudinal Study conducted in the

\section{Author Affiliations}

1. Public Health Ontario, Toronto, ON

2. Manitoba Institute of Child Health, Department of Paediatrics and Child Health, Faculty of Medicine, University of Manitoba, Winnipeg, MB

3. Dalla Lana School of Public Health, University of Toronto, Toronto, ON

4. School of Public Health and Health Systems, University of Waterloo, Waterloo, ON Correspondence: Erin Hobin, PhD, Public Health Ontario, 480 University Avenue, Suite 300, Toronto, ON M5G 1V2, Tel: 647-260-7198, E-mail: Erin.Hobin@oahpp.ca Source of funding: Financial support for this study was provided by the Canadian Institutes of Health Research Population Health Intervention Research Grant.

Conflict of Interest: None to declare. 
UK. ${ }^{16}$ However, available data tracking objectively measured (through accelerometers) ST during childhood and/or adolescence in Canada are sparse. Only recently has Canada incorporated objective measures of ST into its national cross-sectional surveys (i.e., since CHMS 2007-2009).,17 To our knowledge, no studies in Canada have collected longitudinal data to objectively measure adolescents' ST over the course of secondary school. Furthermore, little is known about factors associated with ST trajectories in this population.

Therefore, the purpose of this study was to describe the longitudinal changes in ST among a sample of adolescents in Manitoba between 2008 and 2011 in the context of a provincewide physical education (PE) policy, and to identify student and school-neighbourhood factors associated with ST trajectories.

\section{METHODS}

\section{Study design and population}

This research was conducted as part of a prospective cohort embedded within the Manitoba Increasing Physical Activity in Secondary Students (MIPASS) study evaluating the impact of a province-wide secondary school PE policy on student PA. ${ }^{18}$ Introduced in September 2008, the PE policy mandates students accumulate a minimum of 30 minutes of MVPA per day on at least 5 days per week, in or out of classes. ${ }^{18}$ Details of the Manitoba secondary school PE policy are described elsewhere. ${ }^{18,19}$ Data were collected through a two-stage process whereby secondary schools $(n=31)$ offering grades 9 through 12 with enrolment greater than 100 were randomly selected in blocks to represent the urban and rural geography of Manitoba. ${ }^{18}$ In each selected school, a convenience sample of grade 9 or 10 PE classes was recruited. All students were subsequently screened to exclude those absent at baseline recruitment, unable to perform regular daily living activities, or living with chronic conditions. ${ }^{18}$ Prior to study participation, written informed consent was obtained from parents and assent from students. A total of 596 students in grades 9 and 10 were recruited at baseline. ${ }^{18}$ Of these, $533(89.4 \%)$ students returned the accelerometers at baseline and were followed up once a year until 2011 or grade 12, whichever came first. ${ }^{18}$ Students not meeting the minimum accelerometer wear-time requirement $(n=65)$ or with an extreme MVPA measurement $(n=21)$ at baseline were excluded from the analyses. ${ }^{18}$ Therefore, a total of 447 (75.0\%) students comprised the final sample. ${ }^{18}$ The study received ethics approval from the Nursing and Education Research Ethics Board at the University of Manitoba in accordance with the Declaration of Helsinki. ${ }^{18}$

\section{Accelerometer protocol}

PA and ST were determined objectively with Actical (respironics, Bend, OR) $(n=351)$ and ActiGraph accelerometers (CSA Actigraph, Pensacola, FL) $(n=96)$ over a 7-day period at baseline (2008). Only the Actical accelerometers were used during the follow-up data collection periods (2009 to 2011). Students were instructed to wear the accelerometer on the right hip for 7 consecutive days during waking hours, and only take off the device when bathing or swimming. Acceptable wear time was defined as a minimum of 480 registered minutes ( 8 hours) per day on at least 3 days. ${ }^{18}$ Nonwear time was defined by consecutive zero counts equal to or greater than 60 minutes and those time periods were excluded from the analyses. ${ }^{18}$ Consistent with existing research, raw cutpoints of $<100$ counts per minute (cpm) were used to classify SB and $\geq 1500 \mathrm{cpm}$ as MVPA. ${ }^{20} \mathrm{SB}$ was measured as minutes of ST and $\mathrm{PA}$ as minutes of MVPA.

\section{Study periods}

The baseline period (T0) was in April through June and October 2008, overlapping slightly with the initial policy period. However, we assumed that the policy would not yet have affected students' PA and ST at this point. ${ }^{18}$ The follow-up periods (T1-T6) were defined by the five-month school semesters (e.g., September to January and February to June) in Manitoba between February 2009 and December 2011. ${ }^{18}$ To control for seasonality, participants recruited in the fall and spring semesters were subsequently followed up at the same time each year. To avoid strong seasonality effects, data were not collected in winter.

\section{Assessment of student characteristics}

Using the Youth Health Survey, we collected demographic information on students' age, grade, gender and body mass index (BMI) as calculated from validated measures of self-reported weight and height. ${ }^{18}$ Age was calculated as the difference between date of birth and date of first data collection. ${ }^{18}$ Students' BMI was classified into either healthy weight or overweight/obese according to the age- and sex-specific cut-offs defined by the International Obesity Task Force. ${ }^{18}$ Students with missing height or weight data were classified as missing BMI. Extreme BMI values (i.e., outside of $10-70 \mathrm{~kg} / \mathrm{m}^{2}$ ) were excluded from the analyses. ${ }^{18}$ Students' PA level at baseline was ranked into tertiles of low, moderate and high according to their averaged MVPA minutes per day measured at baseline. $^{18}$

\section{Assessment of school neighbourhood characteristics}

School neighbourhood socio-economic factors were derived by linking school postal codes to the 2006 Canadian census data and the Institut national de santé publique du Québec (INSPQ) material deprivation index. ${ }^{18,21}$ School location was coded as urban or rural where rural was defined as having less than 10,000 according to 2006 census population aged 15 years and older. ${ }^{18,22}$ School neighbourhood socio-economic status (SES) was coded as low or high according to validated material deprivation index from INSPQ. ${ }^{18,21}$ Details of the derivation of the SES variable are described elsewhere. ${ }^{18}$

\section{Statistical analyses}

Descriptive analyses were conducted to describe the distribution of baseline characteristics across the study population and grade cohorts. Linear growth models were fitted to model variations in the outcome that exist within and between individuals. Linear growth models can accommodate unequal spacing of data and missing data in the covariates and over the study period. ${ }^{18}$ To do this, we first ran an unconditional linear growth model by including only a semester variable (T0-T6) in the model to evaluate students' ST at baseline and the amount of change in ST over the study period without adjusting for other covariates (results not shown). Next, five separate conditional linear growth models were run, each adjusting for semester, one of the following 
covariates (i.e., gender, baseline PA, BMI, school location, and neighbourhood SES), and its interaction with semester. Last, three multivariable linear growth models were run adjusting for student characteristics (model 1), school neighbourhood characteristics (model 2), and both student and school neighbourhood characteristics (model 3). The level of statistical significance was selected at $p<0.05$. All analyses were conducted using SAS v. 9.3 software (SAS Institute, Inc., Cary, NC).

\section{RESULTS}

Table 1 presents the demographic characteristics of the study population at baseline by grade cohorts, including $45.6 \%$ females and $53.5 \%$ males. On average, the study population was 15.2 $(\mathrm{SD}=0.82)$ years of age. Tertiles of PA included low $(<36.6$ minutes/day), medium ( $\geq 36.6$ and $\leq 57.1$ minutes/day), and high ( $>57.1$ and $\leq 119.3$ minutes/day). Approximately $51.0 \%$ of students were coded as having a healthy weight and $35.4 \%$ as having missing data for weight status because they either did not report this information or reported biologically implausible values. Nearly $70 \%$ of students attended schools classified as having low neighbourhood SES status, and 70\% attended schools located in urban areas.

\section{Sedentary time at baseline}

Supplementary Table 1 (see ARTICLE TOOLS section on journal site) shows the objectively measured ST data at baseline and followup periods. On average, students contributed $2.6(\mathrm{SD}=1.1)$ time points over the study period. Greater than $76.0 \%$ of students accumulated 480 minutes/day (i.e., 8 hours) of ST or above (see supplementary data). Table 2 describes the estimated effects on students' baseline ST and ST trajectories. At baseline, students accumulated an average of 540 minutes/day (i.e., 9.0 hours) of ST (results not shown). Students with low and moderate baseline PA accumulated an average of 51.2 and 33.9 more minutes/day of ST compared to students with high baseline PA $(p<0.001)$ respectively. Moreover, students with missing BMI status and overweight or obese students accumulated an additional 23.0 $(p=0.005)$ and $6.5(p=0.563)$ minutes/day of ST compared to students with a healthy weight status respectively (Table 2$)$. ST at baseline did not significantly differ by gender $(p=0.320)$, school location $(p=0.774)$ and neighbourhood SES $(p=0.473)$.

\section{ST trajectories}

In the unconditional linear growth model, an average of 545.1 (530.1, 560.2) minutes/day of ST was accumulated at students' last follow-up, representing an increase of $1.0(-1.5,3.5)$ minute/day/ semester from baseline to last follow-up $(p=0.433)$ (results not shown). Further adjustment for school location showed that students attending rural schools had an average decline of 5.3 minutes/day/semester compared to students attending urban schools $(p=0.057)$ (Table 2$)$. In a separate conditional model adjusting for semester and gender, female students showed an average decline of 5.5 minutes/day/semester compared to male students $(p=0.029)$, implying females were becoming less sedentary over time (Figure 1). As shown in Figure 2, students' ST trajectories did not differ by baseline PA levels $(p=0.216)$. There was no evidence that students' ST trajectories differed by BMI status $(p=0.396)$ or neighbourhood SES $(p=0.368)$ when examined in separate conditional linear growth models (Table 2 ).

In the multivariable linear growth model (Table 3 ), we adjusted for gender, baseline PA, BMI status, school location and neighbourhood SES on students' baseline ST and ST trajectories.

Table 1. Demographic characteristics across grade cohorts, total study sample, and baseline sedentary time among students who reported on gender, met minimum accelerometer wear-time requirement of 8 hours per day on 3 days, and were in grades 9 or 10 at baseline

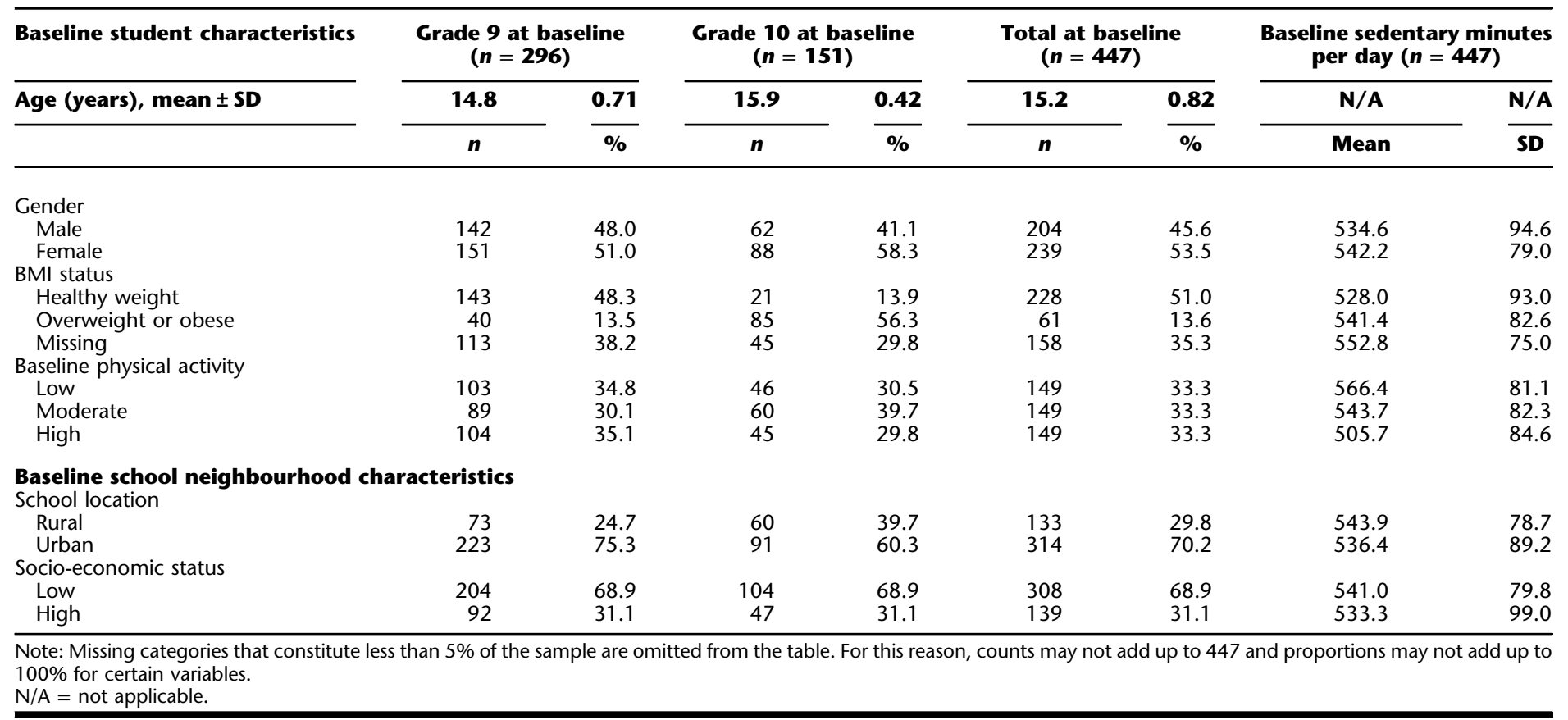


Table 2. Conditional linear growth models examining estimated effect on students' baseline sedentary time and sedentary time trajectories

\begin{tabular}{|c|c|c|c|c|c|}
\hline & & \multicolumn{2}{|c|}{$\begin{array}{c}\text { Estimated effect on baseline sedentary } \\
\text { time (minutes } / \text { day, } 95 \% \mathrm{Cl})\end{array}$} & \multicolumn{2}{|c|}{$\begin{array}{l}\text { Estimated effect on sedentary time } \\
\text { trajectories (minutes/day/semester, } 95 \% \mathrm{Cl} \text { ) }\end{array}$} \\
\hline & & Fixed effect & $p$-value & Fixed effect & $p$-value \\
\hline \multicolumn{6}{|c|}{ Student characteristics } \\
\hline \multirow[t]{2}{*}{ Model 1} & Gender & & & & \\
\hline & Female & $7.52(-7.33,22.36)$ & 0.3202 & $-5.54(-10.51,-0.57)$ & 0.0289 \\
\hline \multirow[t]{2}{*}{ Model 2} & Baseline physical activity & Reterent & & Referent & \\
\hline & $\begin{array}{l}\text { Low } \\
\text { Moderate } \\
\text { High }\end{array}$ & $\begin{array}{l}51.24(33.90,68.58) \\
33.94(16.58,51.30) \\
\text { Referent }\end{array}$ & $\begin{array}{r}<0.0001 \\
0.0001\end{array}$ & $\begin{array}{l}-5.43(-11.58,0.72) \\
-3.62(-9.88,2.63) \\
\text { Referent }\end{array}$ & $\begin{array}{l}0.0835 \\
0.2555\end{array}$ \\
\hline \multirow[t]{2}{*}{ Model 3} & BMI status & & & & \\
\hline & $\begin{array}{l}\text { Overweight or obese } \\
\text { Missing } \\
\text { Healthy weight }\end{array}$ & $\begin{array}{l}6.46(-15.46,28.38) \\
23.04(6.93,39.14) \\
\text { Referent }\end{array}$ & $\begin{array}{l}0.5628 \\
0.0052\end{array}$ & $\begin{array}{l}-1.22(-8.80,6.36) \\
-3.85(-9.41,1.71) \\
\text { Referent }\end{array}$ & $\begin{array}{l}0.7523 \\
0.1744\end{array}$ \\
\hline \multicolumn{6}{|c|}{ School neighbourhood characteristics } \\
\hline \multirow[t]{2}{*}{ Model 4} & School location & & & & \\
\hline & Rural & $2.33(-13.61,18.27)$ & 0.7740 & $-5.32(-10.81,0.16)$ & 0.0572 \\
\hline \multirow{2}{*}{ Model 5} & $\begin{array}{l}\text { Urban } \\
\text { Socio-economic status }\end{array}$ & Referent & & Referent & \\
\hline & $\begin{array}{l}\text { Low } \\
\text { High }\end{array}$ & $\begin{array}{l}5.85(-10.16,21.86) \\
\text { Referent }\end{array}$ & 0.4730 & $\begin{array}{l}-2.57(-8.17,3.03) \\
\text { Referent }\end{array}$ & 0.3683 \\
\hline
\end{tabular}

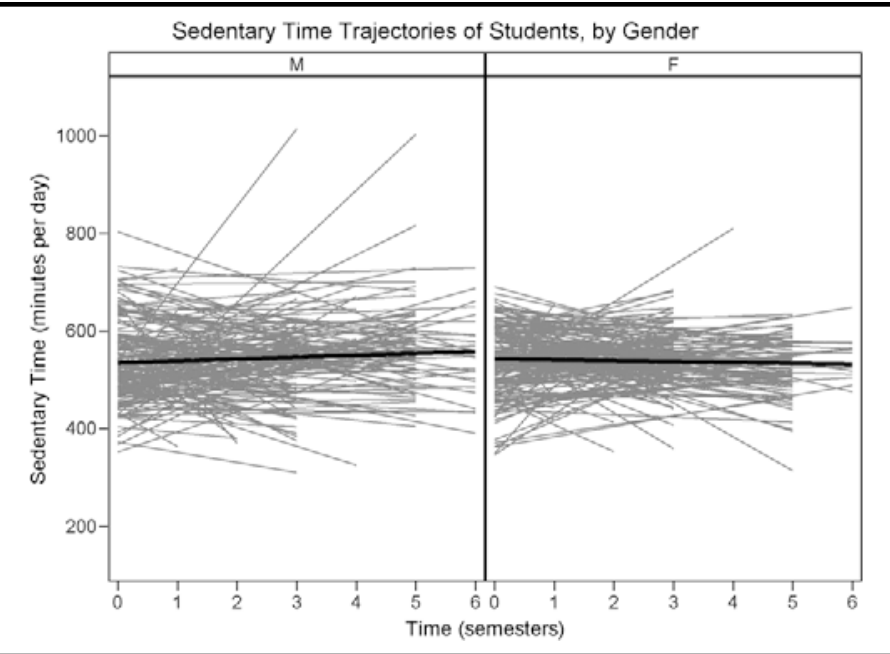

Figure 1. Sedentary time trajectories of students from April 2008 to December 2011, by gender. Linear regressions of sedentary time (minutes per day) across semesters for each student with baseline and at least 1 valid follow-up measurement, by gender, are shown in gray. Linear growth curves showing averaged baseline sedentary time and averaged rate of change in sedentary time among all students, by gender, are shown in black.

Among the student and school neighbourhood factors, only gender was found to be associated with students' ST trajectories ( $p=0.035)$. Compared with males, females' adjusted ST trajectories declined by 5.7 minutes/day/semester $(p=0.035)$. In other words, females' ST significantly decreased compared to males over time. The difference in the adjusted ST trajectories across baseline PA, BMI status, school location, and neighbourhood SES was not statistically significant (Table 3).

\section{DISCUSSION}

Despite the PE policy, ST among Manitoba adolescents remained high and stable at 9 hours per day throughout secondary school. Our findings suggest that SB may be well established by early adolescence (i.e., ages 14 and 15) and track throughout late adolescence. Female gender was the only factor associated with a slight decline in ST over this period. Student characteristics such as baseline PA levels and BMI status, and school neighbourhood characteristics such as school location and SES did not significantly modify adolescents' ST trajectories.

Regardless of baseline PA levels in grades 9 or 10, adolescents maintained an average of 9 hours of ST per day throughout the study period. This observation may be explained in two ways. First, it is possible that the PE policy may have exerted some protective effects against an increase in ST over the course of secondary school among Manitoba adolescents. Second, in accordance with the current paradigm, ST constitutes a distinctive set of behaviours that are unrelated to PA. $^{14}$ There is mounting evidence indicating that adults and adolescents can be physically active and still be considered highly sedentary for engaging in prolonged sitting or other sedentary pursuits. ${ }^{14,23}$ Similarly, results of the current study indicate that adolescents with higher levels of PA may not engage in less amounts of ST over the course of secondary school compared to those with lower levels of PA. Therefore, our findings suggest that, independent of PA, SB may be well established before students reach grades 9 or 10 and remain high throughout adolescence.

Gender may have a role in modifying adolescents' ST trajectories. In this study, female students appeared to be slightly protected against an increase in ST over time. In contrast, the Avon 
Table 3. Multivariable linear growth models examining estimated effect on students' baseline sedentary time and sedentary time trajectories when adjusted for student and school neighbourhood characteristics

\begin{tabular}{|c|c|c|c|c|c|c|}
\hline & \multicolumn{2}{|l|}{ Model 1} & \multicolumn{2}{|l|}{ Model 2} & \multicolumn{2}{|l|}{ Model 3} \\
\hline & \multicolumn{2}{|c|}{ Student characteristics } & \multicolumn{2}{|c|}{$\begin{array}{l}\text { School neighbourhood } \\
\text { characteristics }\end{array}$} & \multicolumn{2}{|c|}{$\begin{array}{c}\text { Student and school } \\
\text { neighbourhood characteristics }\end{array}$} \\
\hline & Fixed effect & p-value & Fixed effect & p-value & Fixed effect & p-value \\
\hline \multicolumn{7}{|c|}{ Estimated effect on baseline sedentary time (minutes/day, 95\% Cl) } \\
\hline \multicolumn{7}{|c|}{ Gender } \\
\hline Female & $2.55(-12.23,17.33)$ & 0.7345 & & & $1.51(-13.45,16.48)$ & 0.8428 \\
\hline Male & Referent & & & & Referent & \\
\hline \multicolumn{7}{|l|}{ Baseline physical activity } \\
\hline Low & $50.31(32.46,68.16)$ & $<0.0001$ & & & $53.39(34.86,71.92)$ & $<0.0001$ \\
\hline Moderate & $32.37(14.86,49.88)$ & 0.0003 & & & $34.77(16.94,52.60)$ & $<0.0001$ \\
\hline High & Referent & & & & Referent & \\
\hline \multicolumn{7}{|l|}{ BMI status } \\
\hline Overweight or obese & $5.63(-15.58,26.84)$ & 0.6021 & & & $4.86(-16.36,26.08)$ & 0.6529 \\
\hline Missing & $23.97(8.05,39.89)$ & 0.0033 & & & $23.99(8.08,39.89)$ & 0.0032 \\
\hline Healthy weight & Referent & & & & Referent & \\
\hline \multicolumn{7}{|l|}{ School location } \\
\hline Rural & & & $-0.39(-18.11,17.33)$ & 0.9654 & $-11.42(-28.84,6.00)$ & 0.1981 \\
\hline Urban & & & Referent & & Referent & \\
\hline \multicolumn{7}{|l|}{ Socio-economic status } \\
\hline Low & & & $6.23(-11.59,24.04)$ & 0.4925 & $3.47(-13.93,20.88)$ & 0.6950 \\
\hline High & & & Referent & & Referent & \\
\hline \multicolumn{7}{|c|}{ Estimated effect on sedentary time trajectories (minutes/day/semester, $95 \% \mathrm{Cl}$ ) } \\
\hline $\begin{array}{l}\text { Gender } \\
\text { Female }\end{array}$ & & & & & & \\
\hline $\begin{array}{l}\text { Female } \\
\text { Male }\end{array}$ & $\begin{array}{l}-5.83(-11.07,-0.59) \\
\text { Referent }\end{array}$ & 0.0293 & & & $\begin{array}{l}-5.70(-11.01,-0.40) \\
\text { Referent }\end{array}$ & 0.0352 \\
\hline \multicolumn{7}{|l|}{ Baseline physical activity } \\
\hline Low & $-3.60(-9.97,2.77)$ & 0.2676 & & & $-2.71(-9.26,3.84)$ & 0.4175 \\
\hline Moderate & $-2.69(-9.01,3.63)$ & 0.4031 & & & $-1.77(-8.24,4.70)$ & 0.5923 \\
\hline High & Referent & & & & Referent & \\
\hline \multicolumn{7}{|l|}{ BMI status } \\
\hline Overweight or obese & $-1.33(-8.84,6.18)$ & 0.7284 & & & $-1.33(-8.90,6.23)$ & 0.7295 \\
\hline Missing & $-4.79(-10.40,0.83)$ & 0.0948 & & & $-5.11(-10.75,0.53)$ & 0.0759 \\
\hline Healthy weight & Referent & & & & Referent & \\
\hline \multicolumn{7}{|l|}{ School location } \\
\hline Rural & & & $-5.07(-11.07,0.93)$ & 0.0975 & $-3.61(-9.78,2.56)$ & 0.2509 \\
\hline Urban & & & Referent & & Referent & \\
\hline \multicolumn{7}{|l|}{ Socio-economic status } \\
\hline Low & & & $-0.51(-6.61,5.59)$ & 0.8702 & $-1.12(-7.31,5.06)$ & 0.7214 \\
\hline High & & & Referent & & Referent & \\
\hline
\end{tabular}

Note: Fixed effects of intercepts for each model are not shown.

$95 \%$ confidence intervals are shown in parentheses.

Referent categories are identified as "referent."

Longitudinal Study conducted in the UK reported that ST increased by 20 and 23 minutes per day per year among male and female adolescents (ages 12 to 16). However, Ortega et al. found no significant differences in ST trajectories between males and females from the European Youth Heart Study (ages 14 to 26). ${ }^{24}$ These inconsistent observations across studies may have resulted from regional differences (i.e., European countries vs. Canada) or differences in the follow-up periods. ${ }^{24}$ The current study is not able to address the inconsistent findings, but reinforces the need to study ST in a gender-specific manner and design future studies to uncover the factors that influence ST among males and females during adolescence.

Currently, the Canadian Sedentary Behaviour Guidelines for Children and Youth recommend adolescents minimize their total ST each day and limit screen time to 2 hours per day or less. ${ }^{1}$ According to the Youth Smoking Survey (YSS 2008-2009), Canadian adolescents on average spend 7.8 hours per day participating in screen-based sedentary pursuits, exceeding the recommended limit by more than 5 hours per day. ${ }^{23}$ Although no guidelines exist with regards to the total amount of daily ST that is appropriate for adolescents, the reduction in ST (2 minutes less per semester) among female students in the current study appears to be minimal relative to an accumulation of 9 hours of ST per day throughout secondary school. There remains potential to further reduce ST for female and male adolescents in Canada. It would be of future interest to investigate how much of the total ST found in our study population was spent on screen-based sedentary pursuits.

The current study differs from other studies by the time period and context during which ST was examined. While others focused on comparing ST in childhood to adolescence, ${ }^{5,25-27}$ or adolescence to adulthood, ${ }^{5}$ this study examined potential longitudinal changes in ST from younger to older adolescence (i.e., ages 14/15 to 18/19) in the context of a province-wide PE policy. Adolescence is a critical developmental stage in the life course for physical and cognitive growth, as well as a transitional period characterized by a growing role in adopting lifestyle practices that may track into adulthood and remain stable throughout life. ${ }^{28}$ As adolescents spend a significant amount of their waking hours in school, ${ }^{29}$ the ongoing PE policy in Manitoba offered an opportunity to potentially influence students' lifestyle, including SB. It is therefore important to measure adolescents' baseline accumulation of ST as they first enter secondary school and track longitudinal changes in ST over the 


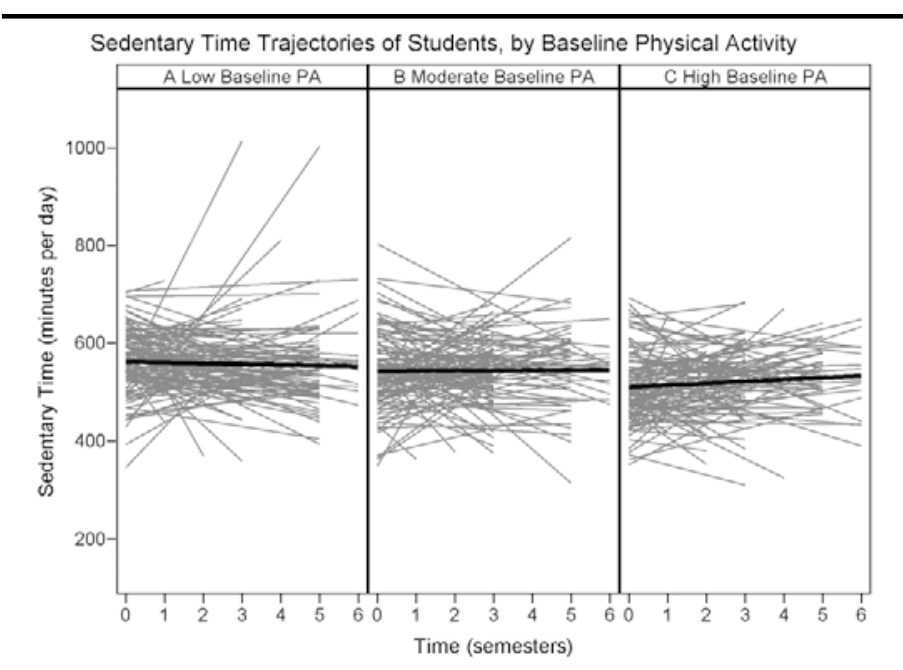

Figure 2. Sedentary time trajectories of students from April 2008 to December 2011, by baseline physical activity. Linear regressions of sedentary time (minutes per day) across semesters for each student with baseline and at least 1 valid follow-up measurement, by baseline physical activity, are shown in gray. Linear growth curves showing averaged baseline sedentary time and averaged rate of change in sedentary time among all students, by baseline physical activity, are shown in black.

course of secondary school in this unique context. The best available ST data in Canada are from CHMS (2012-2013) and are crosssectional in nature. These data report a modest increase of 20 minutes in ST from 9.3 hours per day during adolescence (i.e., ages 12 to 17 ) to 9.6 hours per day during early adulthood (i.e., ages 18 to 39). ${ }^{4}$ Similarly, we also observed a stable trajectory of total ST per day throughout early to late adolescence, suggesting that Canadian adolescents' total ST may track from early adolescence into adulthood. Similar trends have been documented over a 6-year follow-up among Swedish adolescents and a 10-year follow-up among Estonian adolescents. ${ }^{24}$ Collectively, these studies imply that SB is potentially imprinted very early in and remains stable throughout adolescence and early adulthood, and prevention strategies focused on PA alone may not adequately address ST. Future strategies may require a focus on SB and early implementation in children, alongside strategies that promote PA.

\section{Limitations}

This study has limitations. First, a convenience sample of grades 9 and 10 PE classes was recruited from randomly selected schools across Manitoba. As a result, our sample had a higher percentage of participants with healthy weight and meeting the minimum MVPA recommendations at baseline and the last follow-up period compared to the CHMS sample. ${ }^{18}$ Second, active consent may result in differential participation and selection bias. Therefore, findings of this study may not be generalizable to adolescents living in Manitoba and other provinces of Canada. Third, the lack of a concurrent control group unexposed to the PE policy limits our ability to infer that the stable trajectories of ST observed among our study sample was the result of a PE policy promoting PA. Fourth, the baseline data collection period overlapped slightly with the intervention. Although the policy was officially introduced in September 2008, schools required time for implementation. Therefore, we strategically supplemented initial baseline data collected prior to September 2008 with data collected in October 2008. Sensitivity analyses revealed that there were no differences in students' ST at baseline or in the trajectories by time of recruitment (i.e., recruitment before and after September 2008). Fifth, the current study did not present contextual information on the temporal settings and types of SB. As emerging evidence links adverse health outcomes to specific types of SB (e.g., screen time), ${ }^{7,8,13,30}$ it is important to identify whether Canadian students are engaging in certain types of SB more than others over time. Nonetheless, the current study was the first longitudinal investigation of objectively measured ST trajectories and their associated factors among a sample of Canadian adolescents in the context of a PE policy.

\section{CONCLUSION}

Canadian adolescents' total ST per day may remain high throughout secondary school. Manitoba's school-based PE policy targeting PA had minimal influence on a sample of adolescents' ST trajectories over this period. Interventions or policies targeting SB among children may be required to reduce this phenomenon before habitual patterns of SB become established.

\section{REFERENCES}

1. Tremblay M, Janssen I, Kho M, Duggan M, Kicks A, Leblanc A, et al. Canadian Sedentary Behaviour Guidelines for Children (Aged 5-11 Years) and Youth (Aged 12-17 Years): Clinical Practice Guideline Development Report 2011. Ottawa, ON: Canadian Society for Exercise Physiology, 2011.

2. Roberts K, Shields M, Groh MD, Aziz A, Gilbert J. Overweight and obesity in children and adolescents: Results from the 2009 to 2011 Canadian Health Measures Survey. Health Rep 2012;23(3):37-41. PMID: 23061263.

3. Tremblay MS, LeBlanc AG, Kho ME, Saunders TJ, Larouche R, Colley RC, et al Systematic review of sedentary behaviour and health indicators in school-aged children and youth. Int J Behav Nutr Phys Act 2011;8:98. PMID: 21936895. doi: 10.1186/1479-5868-8-98.

4. Statistics Canada. CANSIM Table 117-0020: Average Time Spent Sedentary, Household Population by Sex and Age Group (Minutes per Day), 2015. Available at: http://www5.statcan.gc.ca/cansim/a26?lang=eng\&retrLang $=$ eng\&id $=1170020 \&$ pattern=117-0018.117-0021 \&tabMode=dataTable\&srchLan =-1\&p1=-1\&p2=31 (Accessed July 20, 2015).

5. Levine JA, Lanningham-Foster LM, McCrady SK, Krizan AC, Olson LR, Kane PH, et al. Interindividual variation in posture allocation: Possible role in human obesity. Science 2005;307(5709):584-86. PMID: 15681386. doi: 10.1126/science. 1106561.

6. Hu FB, Li TY, Colditz GA, Willet WC, Manson JE. Television watching and other sedentary behaviours in relation to risk of obesity and type 2 diabetes mellitus in women. J Am Med Assoc 2003;289(14):1785-91. PMID: 12684356 doi: 10.1001/jama.289.14.1785

7. Ekelund U, Brage S, Froberg K, Harro M, Anderssen SA, Sardinha LB, et al. TV viewing and physical activity are independently associated with metabolic risk in children: The European Youth Heart Study. PLoS Med 2006;3(12):e488. PMID: 17194189. doi: 10.1371/journal.pmed.0030488.

8. Ford ES, Kohl HW III, Mokdad AH, Ajani UA. Sedentary behaviour, physical activity, and the metabolic syndrome among U.S. adults. Obes Res 2005; 13(3):608-14. PMID: 15833947. doi: 10.1038/oby.2005.65.

9. Healy GN, Wijndaele K, Dunstan SW, Shaw JE, Salmon J, Zimmet PZ, et al. Objectively measured sedentary time, physical activity, and metabolic risk: The Australian Diabetes, Obesity and Lifestyle study (AusDiab). Diabetes Care 2008;31(2):369-71. PMID: 18000181. doi: 10.2337/dc07-1795.

10. Katzmarzyk PT, Church TS, Craig CL, Bouchard C. Sitting time and mortality from all causes, cardiovascular disease, and cancer. Med Sci Sports Exerc 2009;41(5):998-1005. PMID: 19346988. doi: 10.1249/MSS.0b013e3 181930355.

11. Steele RM, van Sluijs EM, Cassidy A, Griffin SJ, Ekelund U. Targeting sedentary time or moderate- and vigorous-intensity activity: Independent relations with adiposity in a population-based sample of 10-y-old British children. Am J Clin Nutr 2009;90(5):1185-92. PMID: 19776141. doi: 10.3945/ajcn.2009.28153. 
12. Wijndaele K, Brage S, Besson H, Khaw KT, Sharp SJ, Luben R, et al. Television viewing time independently predicts all-cause and cardiovascular mortality: The EPIC Norfold study. Int J Epidemiol 2011;40(1):150-59. PMID: 20576628. doi: 10.1093/ije/dyq105.

13. Owen N, Healy GN, Matthews CE, Dunstan DW. Too much sitting: The population-health science of sedentary behaviour. Exerc Sport Sci Rev 2010; 38(3):105-13. PMID: 20577058. doi: 10.1097/JES.0b013e3181e373a2.

14. Prince SA, Saunders TJ, Gresty K, Reid RD. A comparison of the effectiveness of physical activity and sedentary behaviour interventions in reducing sedentary time in adults: A systematic review and meta-analysis of controlled trials. Obes Rev 2014;15(11):905-19. PMID: 25112481. doi: 10.1111/obr.12215.

15. Matthews CE, Chen KY, Freedson PS, Buchowski MS, Beech BM, Pate RR, et al. Amount of time spent in sedentary behaviours in the United States, 20032004. Am J Epidemiol 2008;167(7):875-81. PMID: 18303006. doi: 10.1093/aje/ kwm390.

16. Mitchell JA, Pate RR, Dowda M, Mattocks C, Riddoch C, Ness AR, et al. A prospective study of sedentary behaviour in a large cohort of youth. Med Sci Sports Exerc 2012;44(6):1081-87. PMID: 22143113. doi: 10.1249/MSS. 0b013e3182446c65.

17. Statistics Canada. Physical Activity of Canadian Children and Youth: Accelerometer Results from the 2007 to 2009 Canadian Health Measures Survey, 2015. Available at: http://www.statcan.gc.ca/pub/82-003-x/2011001/ article/11397-eng.htm (Accessed July 20, 2015).

18. Hobin E, So J, Rosella L, Comte M, Manske S, McGavock J. Trajectories of objectively measured physical activity among secondary students in Canada in the context of a province-wide physical education policy: A longitudinal analysis. I Obes 2014;2014:958645;1-10. PMID: 24672714. doi: 10.1155/ $2014 / 958645$.

19. Manitoba Education, Citizenship and Youth. Implementation of Grades 11 and 12 Physical Education/Health Education: A Policy Document, 2007. Available at: http://www.edu.gov.mb.ca/k12/docs/policy/imp_pehe/ document.pdf (Accessed July 20, 2015).

20. Colley RC, Wong SL, Garriguet D, Janssen I, Gorber SC, Tremblay MS. Physical activity, sedentary behaviour and sleep in Canadian children: Parent-report versus direct measures and relative associations with health risk. Health Rep 2012;23(2):45-52. PMID: 22866540.

21. Institut national de santé publique du Québec. Deprivation Index, Québec, 2006. Available at: http://www2.inspq.qc.ca/santescope/indicedefavoeng. asp?NoIndD=4\&Lg=en (Accessed July 20, 2015).

22. Statistics Canada. Population and Dwelling Counts, for Canada, Provinces and Territories by the Statistical Area Classification, 2006 and 2001 Censuses 100\% Data, 2010. Available at: http://www12.statcan.gc.ca/census-recensement/ 2006/dp-pd/hlt/97-550/Index.cfm?TPL=P1C\&Page=RETR\&LANG=Eng\&T=601 $\& \mathrm{PR}=46 \& \mathrm{~S}=0 \& \mathrm{O}=\mathrm{D} \& \mathrm{RPP}=25$ (Accessed July 20, 2015).

23. Leatherdale ST, Ahmed R. Screen-based sedentary behaviours among a nationally representative sample of youth: Are Canadian kids couch potatoes? Chronic Dis Inj Can 2011;31(4):141-46. PMID: 21978636.

24. Ortega FB, Konstabel K, Pasquali E, Ruiz JR, Hurtig-Wennlöf A, Mäestu J, et al. Objectively measured physical activity and sedentary time during childhood, adolescence and young adulthood: A cohort study. PLoS One 2013;8(4): e60871. PMID: 23637772. doi: 10.1371/journal.pone.0060871.

25. Treuth MS, Hou N, Young DR, Maynard LM. Accelerometry-measured activity or sedentary time and overweight in rural boys and girls. Obes Res 2005; 13(9):1606-14. PMID: 16222064. doi: 10.1038/oby.2005.197.

26. Janz KF, Burns TL, Levy SM, Iowa Bone Development Study. Tracking of activity and sedentary behaviours in childhood: The Iowa Bone Development Study. Am J Prev Med 2005;29(3):171-78. PMID: 16168865. doi: 10.1016/j. amepre.2005.06.001.

27. Pate RR, Stevens J, Pratt C, Sallis JF, Schmitz KH, Webber LS, et al. Objectively measured physical activity in sixth-grade girls. Arch Pediatr
Adolesc Med 2006;160(12):1262-68. PMID: 17146024. doi: 10.1001/ archpedi.160.12.1262.

28. Dunn JE, Liu K, Greenland P, Hilner JE, Jacobs DR Jr. Seven-year tracking of dietary factors in young adults: The CARDIA study. Am J Prev Med 2000 18(1):38-45. PMID: 10808981. doi: 10.1016/S0749-3797(99)00114-2.

29. Hills AP, King NA, Armstrong TP. The contribution of physical activity and sedentary behaviours to the growth and development of children and adolescents. Sports Med 2007;37(6):533-45. PMID: 17503878. doi: 10.2165/ 00007256-200737060-00006

30. Dunstan DW, Barr EL, Healy GN, Salmon J, Shaw JE, Balkau B, et al. Television viewing time and mortality. The Australian Diabetes, Obesity and Lifestyle Study (AusDiab). Circulation 2010;121(3):384-91. PMID: 20065160. doi: 10. 1161/CIRCULATIONAHA.109.894824.

\section{RÉSUMÉ}

OBJECTIFS: Le comportement sédentaire (CS) des adolescents canadiens est mal compris et beaucoup moins étudié que leur activité physique (AP). Les données qui s'accumulent laissent croire que le CS pose des risques à long terme pour la santé, indépendamment des niveaux d'AP. Pour concevoir des interventions efficaces qui ciblent le CS, il est indispensable de comprendre d'abord les trajectoires du temps de sédentarité (TS) des adolescents dans un contexte canadien. C'est pourquoi nous avons examiné les trajectoires longitudinales du TS d'élèves du Manitoba de 2008 à 2011 et répertorié les facteurs associés dans le contexte d'une politique d'éducation physique (ÉP) provinciale.

MÉTHODE: Des écoles secondaires offrant des classes de la $9^{\mathrm{e}}$ à la $12^{\mathrm{e}}$ année ont été sélectionnées au hasard en blocs pour représenter la géographie urbaine et rurale du Manitoba. Dans chaque école sélectionnée $(n=31)$, nous avons recruté un échantillon de commodité de classes d'Ép de $9^{\mathrm{e}}$ ou de $10^{\mathrm{e}}$ année, ce qui a donné un échantillon final de 447 élèves. Pour l'évaluation du TS, les participants ont porté des accéléromètres pendant 7 jours consécutifs au départ (2008) et durant au moins une période de suivi $(2009,2010$ et 2011).

RÉSULTATS: Au départ, les élèves ont accumulé 480 minutes/jour de TS. Durant leurs études secondaires, les trajectoires du TS des élèves sont restées stables. Comparativement aux garçons, les filles ont affiché un taux de diminution du TS légèrement supérieur $(p=0,035)$, compte tenu des variables sociodémographiques. Les trajectoires du TS n'étaient pas associées à I'AP de départ, à l'indice de masse corporelle, ni au statut socioéconomique du quartier de l'école.

CONCLUSION: Le TS des adolescents est resté élevé durant toutes leurs études secondaires. Le CS pourrait être bien ancré dès le début de l'adolescence et se poursuivre jusqu'à la fin de l'adolescence. Nos constatations indiquent que des interventions supplémentaires pourraient être nécessaires pour réduire le CS avant et durant les études secondaires.

MOTS CLÉS: temps de sédentarité; modèle de croissance linéaire; analyse longitudinale 